\title{
O NÚCLEO GUEL ARRAES, DA REDE GLOBO DE TELEVISÃO, E A CONSAGRAÇÃO CULTURAL DA "PERIFERIA"
}

Desde a década de I980, uma geração de artistas e intelectuais tem contestado a oposição entre "alta" e "baixa" culturas e se valido de seu capital midiático para produzir programas de TV em que despontam uma nova estrutura de sentimentos anti-intelectualista, apegada ao valor da "diversidade", refratária ao nacionalismo, ao partidarismo e a uma visão tradicionalista de "povo". Esta geração tem no Núcleo Guel Arraes (NGA), da Rede Globo, um espaço institucional e simbólico muito importante. Para entender esta estrutura de sentimentos e apontar de que maneira ela ecoa e intensifica uma mudança no campo cultural brasileiro, este artigo está dividido em dois itens. No primeiro, temos uma análise da estrutura de sentimentos dos artistas e intelectuais abrigados no NGA, feita a partir de uma pesquisa realizada em conjunto com Yvana Fechine, que contemplou entrevistas com Guel Arraes e a consulta a fontes secundárias obtidas em livros, sites, revistas e dissertações sobre o tema. No segundo item, é possível discutir em que medida a contestação da dualidade entre a "alta" e "baixa" culturas emerge da visibilidade midiática da periferia, que é um dos desdobramentos mais importantes daquela estrutura de sentimentos e uma tônica muito presente nos programas do NGA. Esta análise versa principalmente sobre o programa dominical Esquenta exibido em 24 de junho de 20I2, selecionado em função da riqueza do material que disponibiliza para o tratamento daquela questão. 
Antes de mais nada, cabe justificar o uso do conceito de "estruturas de sentimento". Ele foi apresentado por Raymond Williams como uma alternativa aos conceitos de "ideologia" e de "visão de mundo" que, segundo ele, estariam restritos às crenças sistematizadas de um grupo ou classe social (Williams, 2000: I54). Mais abrangente, a estrutura de sentimentos inclui "os valores tal como são vividos ativamente" e a dimensão afetiva da consciência, sem deixar de lado as crenças formais que também fazem parte dela. Além disso, seu caráter mais fluido está ligado também ao fato de que se volta a processos em formação, ainda não institucionalizados em projetos e manifestos, mesmo que seja mais reconhecível a posteriori, como um certo ar de família presente nas obras de artistas e intelectuais que respondem às mudanças de seu tempo a partir de valores partilhados. Ela pode se manifestar como sentimentos e ritmos específicos, tipos de sociabilidade e figuras semânticas (formas e convenções) recorrentes no interior das obras (Williams, 2000: I56). No caso do Núcleo Guel Arraes, a análise tenta mostrar que certas características da estrutura de sentimentos dos seus artistas e intelectuais já estavam presentes nas suas produções anteriores ao ingresso na Globo. Ao mesmo tempo, a formação do Núcleo e seus desdobramentos marcam uma institucionalização daquela estrutura de sentimentos que vai assumir, cada vez mais, a forma de um projeto estético-político analisado no final do artigo, especialmente visível na atuação do próprio Guel Arraes, do antropólogo Hermano Vianna e de Regina Casé.

Isto nos coloca diante de um segundo aspecto importante do conceito de estrutura de sentimentos: o da relação entre o grupo, a geração e a sociedade. Ele aponta para formas e convenções artísticas entendidas como "elementos inalienáveis de um processo material social", como "uma formação social de tipo específico que por sua vez, pode ser definida como articulação de estruturas de sentimento que, como processos vividos, são experimentadas muito mais amplamente" (Williams, 2000: 156). Temos, assim, um conceito aplicável a diferentes dimensões da organização social. Em primeiro lugar, em sentido mais rigoroso, ele distingue a produção de um grupo particular de artistas e intelectuais. Em segundo lugar, “já que o que estamos definindo é uma qualidade particular da relação e da experiência social, historicamente distinta de quaisquer outras qualidades particulares, que determina o sentido de uma geração e de um período" (Williams, 2000: I57), ele tem uma dimensão temporal que permite pensar a sucessão entre as distintas gerações. E, por fim, deixando em aberto a questão de determinar o tamanho da influência deste grupo na formação de uma nova estrutura de sentimentos de apelo mais amplo, o fato de que esta simboliza uma experiência social particular expande o seu significado muito além deste grupo, alcançando, potencialmente, o conjunto da sociedade em que aquela experiência tem lugar através das produções do grupo específico de artistas e intelectuais. 


\section{O NÚCLEO GUEL ARRAES: ESTRUTURA DE SENTIMENTOS E ATUAÇÃo MIDIÁTICA}

Por várias razões, o Núcleo Guel Arraes, da Rede Globo de Televisão, é um ponto de observação privilegiado de uma mudança no campo cultural brasileiro. Em primeiro lugar, é indicativo da emergência de uma nova estrutura de sentimentos predominante entre artistas e intelectuais desde cedo socializados pela indústria cultural, e que ganharam espaço profissional a partir da década de I980, em contraste com a geração anterior, marcada por uma estrutura de sentimentos de brasilidade revolucionária (Ridenti, 2000). Isto significa que as pretensões vanguardistas e as linguagens da mídia podem estar lado a lado entre os membros desta geração. Em segundo lugar, atestam que o capital midiático pode, sim, ser reconvertido em capital simbólico a contestar a legitimidade da divisão entre "alta" e "baixa" culturas em outros âmbitos. Tais artistas e intelectuais atuam no sentido da superação da dualidade entre uma concepção modernista de cultura erudita e uma visão mais estática de cultura popular e, neste sentido, clamam por uma redefinição do próprio campo cultural brasileiro ao transferirem o montante de capital simbólico de que dispõem para gêneros pouco consagrados naquele campo, como o funk, o tecnobrega, o hip hop.

O NGA atuou como uma porta de entrada, na Globo, para artistas e intelectuais ligados a circuitos de produção reconhecidos como independentes, nas áreas do vídeo, do teatro e do jornalismo. A assimilação de artistas pela indústria, como mostrou Ridenti em relação à $\mathrm{TV}$, e como demonstrei em relação à publicidade (Ridenti, 2000: 324; Rocha, 20I0: cap. I), se intensifica desde, pelo menos, a década de I960, mas tem no Núcleo Guel Arraes um ponto de culminância, uma vez que tal incorporação dos produtores culturais se faz de maneira expressa e propositada, de modo a fornecer à Globo um espaço de experimentação e uma legitimidade muito necessários no contexto de crescente contestação de seu poder, tanto no mercado televisivo quanto na sociedade civil.

Em outra ocasião, tratei das razões econômicas e políticas que levaram a Globo a abrir este espaço de experimentação através do Núcleo Guel Arraes (Rocha, 2008a). Mudando a perspectiva, é importante analisar as concepções sobre política e cultura desta geração de artistas e intelectuais, bem como as suas motivações para introduzir estas concepções na TV, na forma de programas que atendem ao duplo critério de boas médias de audiência e reconhecimento de críticos (Machado, 2000).

Comecemos pelo próprio Guel Arraes. Enquanto outros de sua geração viviam gradualmente as mudanças da sociedade brasileira nos anos I970, Guel Arraes topou com elas subitamente na sua volta ao Brasil, no final de I979. Isso impôs uma nota singular em sua biografia, tanto mais porque Guel 
respondeu reelaborando, de maneira muito consciente, a sua formação política e cultural, as influências do Cinema Novo, de Jean Rouch e do pai, Miguel Arraes, político exilado no pós-I964. Todo esse legado perdeu o chão quando, na volta ao Brasil, ele encontrou uma indústria cultural consolidada, uma geração de criadores refratária ao nacional-popular e à política partidária, um certo clima de "desbunde" festivo em que ecoavam as contraculturas da década de ig6o.

Miguel Arraes de Alencar Filho viu-se, indiretamente, condenado ao exílio quando o pai foi deposto pelo Regime Militar, em I964. Da Argélia, país que abrigou a família Arraes, Guel partiu para a França, onde realizou seus estudos universitários em antropologia. No curso, teve o primeiro contato com o cinema. Buscou, então, dos I8 aos 25 anos, uma formação quase autodidata nessa área. Assistia às sessões da Cinemateca Francesa, admirava os cineastas russos, a Nouvelle Vague, o Cinema Novo. Sofreu, também, grande influência de Jean Rouch, um dos criadores do "cinema verdade" e diretor do Comitê do Filme Etnográfico, onde entrou em I973, como estagiário, e acabou trabalhando até 1979, quando deixou Paris.

De volta ao Brasil, na virada do ano de I980, Guel foi morar no Rio de Janeiro, onde trabalhou com a produção de curta-metragens até surgir a oportunidade de atuar como assistente de câmera no filme $O$ beijo no asfalto (I980), de Bruno Barreto. Durante as filmagens, conheceu o ator Tarcísio Meira e, através dele, foi apresentado a Paulo Ubiratan. Partiu dele o convite para estagiar na Globo. Seu aprendizado na TV começou justamente com um dos seus formatos mais conservadores: a telenovela. Trabalhando com o escritor Silvio de Abreu e com o diretor Jorge Fernando, Guel colaborou, entre I98I e I985, com a direção de três novelas: Jogo da vida, Guerra dos sexos e Vereda tropical, marcadas por sua natureza paródica, uma característica de vários outros programas dirigidos por ele posteriormente. Foi nessa época que ele se abriu para novas influências: de um lado, o cinema primitivo, mudo e burlesco europeu; de outro, as chanchadas brasileiras e os programas da TV Viva de Olinda. Juntando as novas e as velhas influências, Guel estava pronto para dirigir o seu primeiro seriado, Armação ilimitada. Depois dele, veio o humorístico TV Pirata. Os dois programas foram um marco na linguagem da TV brasileira e alavancaram a sua bem-sucedida carreira na Globo. Em I99I, ele assumiu o comando do núcleo que leva seu nome, no qual vem trabalhando, desde então, como diretor, roteirista e produtor artístico. A partir de I999, Guel passou a conciliar o trabalho na TV com o cinema, atuando como diretor, roteirista ou produtor em filmes como O auto da compadecida (I999), Caramuru - A invenção do Brasil (2000), Lisbela e o prisioneiro (2003), O coronel e o lobisomem (2005), e A grande família (2007). 
Vejamos como Guel descreve sua formação:

Eu vivi em um ambiente extremamente politizado. Acho que o interesse pelo cinema veio como uma alternativa para conciliar uma identificação, de certo modo, com os ideais políticos do meu pai, e com a vontade de todo filho de se diferenciar do pai, seguindo seu próprio caminho. Havia, ainda, a influência grande do Cinema Novo, pelo qual me apaixonei. Por isso, me senti na obrigação de fazer um cinema político, de alguma maneira. O cinema do Rouch apontou caminho novo para mim. Era um cinema voltado para a realidade social, mas não tinha um conteúdo político partidário. Eu acho que foi isso o que mais me encantou: com esse tipo de filme, eu não precisaria jogar fora o que tinha aprendido em casa, o olhar interessado pelas manifestações populares, mas também não precisava me ocupar do documentário engajado politicamente, que não me interessava, até pela vontade de me diferenciar (entrevista concedida à autora em 2007 e disponível, na integra, em Fechine et al., 2008).

Sua fala sugere uma reelaboração que, talvez de uma maneira menos drástica, foi necessária a muitos de sua geração: de um lado, o Cinema Novo e o pai, com seu engajamento político direto e sua aposta numa figura mais uniforme de povo, de matiz rural; de outro, o desejo de imprimir uma marca pessoal em sua trajetória e as influências de um contexto renovado, em que aquelas aspirações revolucionárias pareciam deslocadas diante da solidez do capitalismo, da crise da esquerda tradicional e da sua crítica pelos movimentos contraculturais da década de I960. Estes últimos contribuíram muito para o descrédito dos mecanismos da política institucionalizada, e tinham muito mais na arte do que no partido ou no sindicato, o seu canal de expressão. $O$ temor de fazer uma "arte partidária" que Guel manifesta é partilhado por muitos de sua geração e traça uma primeira diferença importante em relação àquela "estrutura de sentimentos de brasilidade revolucionária" (Ridenti, 2000), do período anterior.

Chegando ao Rio, Guel deparou-se com o "desbunde" e sua desconfiança para com o nacional-popular, já bastante convertido em ideologia durante a ditadura. Os movimentos contraculturais da década de I96o repercutiam no cenário nacional de modo que a transformação social e seus agentes deixavam de ser pensados em termos estritamente classistas para dar lugar a uma visão mais diversificada e mais fragmentária da política. De início, seu trabalho de codireção em novelas não deixava muito espaço para a manifestação dessas ambiguidades de criador, formado dentro de uma visão política e cultural com ecos esquerdistas, atuando no seio da indústria cultural. Pelo contrário, funcionou como uma verdadeira ressocialização em que sua formação cinematográfica foi convertida em recurso para a construção de narrativas televisuais. Porém, quanto mais espaço ele ganhava dentro da Globo, mais o seu trabalho expressava a busca por um caminho em que aquele legado do cinema político e etnográfico pudesse ser reelaborado substantivamente com a demanda por audiência. Neste projeto, ele não esteve sozinho. Pelo contrário, funcionou como um articulador entre a Globo e profissionais de diferentes áreas da produção cultural. 
O NGA foi o ponto de convergência de artistas oriundos de três polos diferentes de produção cultural: o teatro alternativo do Asdrúbal Trouxe o Trombone, o vídeo independente e o jornalismo nanico do Casseta Popular e do Planeta Diário. Yvana Fechine apresenta uma análise bastante detalhada da formação do grupo e das trajetórias de seus membros (2008). Aqui faremos apenas uma síntese de maneira a ressaltar algumas características da estrutura de sentimentos que marcam esta geração de artistas abrigada no NGA.

Do jornalismo alternativo veio Cláudio Paiva, um dos roteiristas mais importantes do NGA, que trabalhou como redator no Pasquim e fundou o Planeta Diário em I984, um tabloide de humor. Reinaldo e Hubert também trabalharam no Pasquim e, juntamente com Paiva, participaram da revista Casseta Popular, que, desde I978, era publicada por estudantes de engenharia da UFRJ, ligados ao PCB, entre eles, Beto Silva, Helio de La Peña e Marcelo Madureira, aos quais se juntaram, em I980, Claudio Manoel e Bussunda. Hélio de La Penã lembra que decidiram criar o "jornalzinho" justamente para "sacanear" os caras "sérios" e "sisudos" com os quais disputavam espaço no movimento político estudantil, e aqui temos outra vez a reformulação da ideia de liberdade em termos cada vez menos partidários, ideia esta que já vimos expressa por Guel Arraes e que caracteriza a estrutura de sentimentos deste grupo (ver A história completa..., 2005: I6).

Voltando à formação do grupo, as duas publicações citadas mantinham o mesmo espírito de sátira política e de costumes. Parodiando a própria imprensa, a Casseta Popular chegou a estampar na capa a manchete "Caçador de maracujás", em alusão ao então candidado à presidência do Brasil, Fernando Collor de Mello. Também criavam legendas absurdas para fotos verdadeiras e publicavam anúncios publicitários de produtos que não existiam. O próprio título Planeta Diário é uma alusão ao jornal em que trabalhava o personagem Clark Kent, o super-homem. Aqui é possível destacar uma segunda característica da estrutura de sentimentos desta geração de artistas e intelectuais: o diálogo mais intenso com os temas, técnicas e formatos da indústria cultural, o que, em última instância, acaba tornando problemática a distinção entre "alta" e "baixa" culturas, já que temos uma produção abrigada no seio da indústria cultural, mas que não abdica de uma justificação política e estética em certo sentido semelhante a das vanguardas modernistas. Por um lado, este grupo recupera o projeto de representar os "oprimidos", não mais situados no mundo rural e tradicional, mas nas periferias das grandes cidades, o que está em compasso com a urbanização da sociedade praticamente completada na década de I980. Por outro lado, estes artistas e intelectuais tampouco renunciam ao primado da inovação estética, mesmo que agora tenham muito mais dificuldades em negociá-lo com os ditames da estrutura burocrática e capitalista na qual tem lugar a sua produção. 
Ainda sobre o filão do jornalismo nanico na formação do NGA, aqueles dois grupos convergiram para constituir o Casseta \& Planeta, com exceção de Cláudio Paiva, contratado pela Globo desde 1987, que preferiu atuar sozinho como roteirista. Atualmente, é redator-final de A grande família, o mais longevo e bem-sucedido programa do grupo em termos de audiência. Já a trupe Casseta \& Planeta ganhou programa próprio, o Casseta \& Planeta Urgente!, em I992, inicialmente produzido pelo Núcleo Walter Lacet, e transferido para o NGA em I998. O tipo de humor praticado pelo Casseta, segundo seu diretor José Lavigne, tem uma relação direta com o "teatro besteirol" dos anos I980, no qual ele próprio se formou, assim como Pedro Cardoso, que colaborou com o programa e é um nome muito atuante no Núcleo.

O vídeo independente dos anos 1980 foi outra fonte de profissionais para os projetos do NGA, em especial, Marcelo Tas, Fernando Meirelles, Sandra Kogut e Jorge Furtado. Os dois primeiros fundaram a produtora Olhar Eletrônico, responsável por uma das primeiras experiências de parceria entre a televisão comercial e a produção videográfica no Brasil. Sua marca principal era a paródia às propostas, personagens e procedimentos da TV, como nos célebres quadros em que Ernesto Varela, personagem de Tas, entrevistava políticos no Congresso Nacional. Essa sátira aos meios a partir dos meios, presente tanto no jornalismo nanico do Casseta quanto nesta vertente do vídeo independente, se manifesta claramente no TV Pirata, programa fundamental para que o NGA adquirisse uma assinatura própria.

A TV Viva, de Olinda, Pernambuco, também influenciou o Núcleo através de seu próprio criador. Ela consta como a primeira televisão de rua brasileira direcionada aos movimentos sociais. Segundo Fechine, em meados dos anos I990, a TV Viva produzia, a cada I5 dias, um programa de variedades que era exibido em telões nos bairros periféricos da região metropolitana de Recife (Fechine, 2008: 24). Tal proposta convergiu com a formação voltada ao vídeo etnográfico que Guel Arraes adquiriu em contato com o diretor Jean Rouch. Uma abordagem mais antropológica de temas e personagens se manifesta, por exemplo, no Programa Legal que, misturando humor e documentarismo, abordou desde os bailes funk da periferia, às festas de debutante. Com um espírito semelhante, o Brasil Legal, dirigido por Sandra Kogut, mostrava "diferentes regiões do país a partir de valores e vivências de seus personagens - tipos divertidos e inteligentes, como Mário Pezão, ex-menino de rua e cantor de rap; D. Flora, neta de índios e vendedora de ervas ou Glauber Moscabilly, adepto do rock dos anos 6o" (Fechine, 2008: 25).

Já a parceria com Fernando Meirelles culminou no episódio Palace II, exibido no final de 2000 , dentro da série Brava Gente. Ele funcionou como uma preparação para o filme Cidade de Deus (2002), dirigido por Meirelles, que, por sua vez, orientou a produção do seriado Cidade dos Homens na TV (2002-2005). $\mathrm{O}$ seriado tem como protagonistas dois garotos que enfrentam problemas 
comuns a moradores de favelas do Rio de Janeiro. Como lembra Fechine "Cidade dos Homens colocou, na tela da Globo, gente fumando maconha, apontando armas para a câmera, falando palavrões e apanhando da polícia, ensaiando, ainda que de modo superficial, uma aproximação com a representação do universo sociocultural das periferias das grandes cidades" (Fechine, 2008: 25).

O maior colaborador de Guel Arraes vindo do vídeo independente é o gaúcho Jorge Furtado, sócio-fundador da produtora Casa de Cinema de Porto Alegre. Furtado foi roteirista, entre outros, do Programa Legal, do Brasil Legal, de Dóris para Maiores e do seriado Comédia da Vida Privada. Assim como Meirelles, ele participa da aproximação entre TV e cinema a partir de sua colaboração com Guel no roteiro e direção da minissérie A Invenção do Brasil (2000), remontada depois como filme.

O terceiro filão de artistas que participou da formação do NGA foi o grupo de teatro Asdrúbal Trouxe o Trombone, que teve início em meados dos anos I970, em diálogo com o cinema underground e a poesia marginal. Segundo Heloísa Buarque de Holanda, o "espírito Asdrúbal" pode ser descrito como uma disposição para a subversão dos cânones e padrões teatrais da época, notadamente o "teatro de resistência" que assumia franca contestação ao Regime Militar. Ainda segundo ela, o Asdrúbal abriu espaço para o "livre trânsito entre Tchaikovsky e os Beatles, o texto clássico e os comerciais de TV, a persona dramática e a pessoa do ator" (Holanda, 2004: I0). Interessa destacar o caráter anti-intelectualista do teatro do Asdrúbal e a incorporação deliberada de elementos da cultura pop, notadamente os formatos da TV, marcas da estrutura de sentimentos deste grupo de artistas e intelectuais.

$\mathrm{Na}$ TV, a atuação dos artistas ligados ao Asdrúbal ganhou forma com o seriado Armação Ilimitada, que parodiava os próprios seriados televisivos, incorporando vários elementos da cultura "pop", especialmente dos videoclipes e histórias em quadrinhos. Patrícia Travassos trabalhou como roteirista em Armação, enquanto Louise Cardoso, Evandro Mesquita e Luiz Fernando Guimarães atuaram como atores no mesmo seriado.

Regina Casé, que também trabalhou em Armação, fez parte do grupo fundador do Asdrúbal. Mais tarde, atores e diretores ligados àquele grupo de teatro se reencontraram no TV Pirata. Segundo Regina Casé, este programa "foi muito importante e marca o meu reencontro com o Luiz (Fernando Guimarães) depois do Asdrúbal. O grupo, aliás, foi completamente impregnado pelo espírito do Asdrúbal que nós trazíamos" (depoimento publicado no site pessoal de Regina Casé). Esta atriz tem um interesse especial porque esteve ligada às produções do NGA que mais tematizaram as culturas populares urbanas, lastreadas em circuitos comerciais distantes da grande mídia, pelo menos, inicialmente. Nos programas em que atuou, Regina Casé explorou o mesmo tipo de atuação, baseada na performance legada pela experiência do 
Asdrúbal, uma mistura de atriz e apresentadora. Ligada ao diretor Guel Arraes desde as primeiras novelas em que ele trabalhou, Regina Casé atuou no programa humorístico TV Pirata e, desde então, tem participado dos projetos mais inovadores do grupo. Na década de I990, protagonizou o Programa Legal (I99I-I993) e o Brasil Legal (I995-I997) e, depois, assumiu o comando do Muvuca (1998-2000), entre outros. Ela também colaborou como diretora em Cena Aberta (2003).

Em 2006, ela estreou o programa Central da Periferia, que, uma vez por mês, levava às telas da Globo, no formato de um grande show, as manifestações culturais que têm proliferado nos bairros pobres das grandes capitais. Assim, aos poucos foi ganhando forma dentro do Núcleo, a tendência à representação dos "invisíveis" sociais em que se assenta boa parte da legitimidade alcançada por seu projeto estético-político e que tem sido fundamental para a reconstrução da imagem da emissora, abalada por sua associação com o Regime Militar e com políticos direitistas durante a redemocratização (Rocha, 2008a).

\section{A VISIBILIDADE DA PERIFERIA E O CASO DO PROGRAMA DOMINICAL ESOUENTA}

Dentro do grupo, convém destacar, para os propósitos deste artigo, o projeto de visibilidade afirmativa da "periferia" encampado, sobretudo, pelo trio formado por Guel Arraes, Regina Casé e o antropólogo Hermano Vianna, consultor e redator de vários programas. Já na sua dissertação de mestrado defendida em 1987, Hermano Vianna descreve seu contato com o funk carioca. Ele começou através da rádio Tropical, que tinha um programa em que eram anunciados dezenas de bailes no fim de semana. Até que decidiu frequentar os bailes e escrever um artigo para o Jornal do Brasil sobre a influência da música negra internacional no carnaval de Salvador e do Rio de Janeiro (Vianna, I987: 4). Desde a onda do Black Rio, em I976, alardeada pelos jornais, era a primeira vez que se escrevia sobre as enormes festas suburbanas, agora em sua "fase hip hop". O interesse despertado na imprensa, por sua vez, consolidou o propósito de estudar o funk quando uma reportagem da TVE o colocou em contato com os DJs Marlboro, Batata e Rafael. Foi assim que, segundo Vianna, ele virou uma espécie de "tradutor" do funk para a Zona Sul, levando discotecários para tocar lá e dando opiniões aos DJs (Vianna, I987: 5).

É interessante destacar, assim, o papel da mídia em dar o estatuto de "realidade" a um fenômeno que atraía cerca de um milhão de jovens a cada final de semana, no Rio, e que já existia há quase duas décadas ao ser "descoberto". O próprio Vianna aponta que o uso deste termo "denuncia a relação que a grande imprensa do Rio mantém com o subúrbio, considerados sempre um territó- 
rio inexplorado, selvagem, onde um antropólogo pode descobrir 'tribos desconhecidas', como se estivesse na Floresta Amazônica” (Vianna, I987: 5). Passados cerca de I5 anos desde a pesquisa de Vianna, é possível dizer que sua atuação no Núcleo Guel Arraes contribuiu fortemente para levar a "periferia" à maior televisão do país, tendência que alcançou mais recentemente até a telenovela, com a crescente representação de favelas, subúrbios e a adesão ao tecnobrega em Cheias de Charme, além do sucesso estrondoso que foi Avenida Brasil.

Desde as décadas de I960 e I970, a ampliação de mercados culturais nos quais passaram a circular o rock e a música negra americana teve um papel importante na disseminação destes ritmos no Brasil, até o ponto em que eles passaram a ser produzidos e reelaborados também no país. O adensamento desta cultura pop é uma condição material importante para a compreensão da estrutura de sentimentos desta geração, que passou a utilizar estes ritmos para se diferenciar do nacionalismo, já muito associado ao Governo Militar.

Sob forte inspiração das pesquisas de Vianna, George Yúdice salienta que a democratização dos I980 e I990 "trouxe à baila a inviabilidade da emancipação social e política através de práticas culturais que faziam parte de um 'consenso', em virtude do qual se repartia a riqueza material para as elites e as dificuldades, cada vez maiores, para as classes subalternas. Hoje, a cena cultural está em rápido processo de mutação, refletindo a insatisfação crescente com a nação" (Yúdice, 2004: I60-I6I). Eis o contexto para o surgimento de fortes críticas à identidade nacional brasileira, especialmente pelos movimentos de rap da juventude negra, confrontando a maneira pela qual a "cultura do consenso simbolizou práticas como o samba, o pagode, a capoeira, o candomblé e a umbanda, e assim por diante" (Yúdice, 2004: I6I).

Enquanto outros setores continuam investindo no nacionalismo cultural, inclusive a própria Globo, a "juventude subalterna" abriu novos caminhos em contato com formas culturais transnacionais, nem sempre de maneira tão politizada quanto o rap. Yúdice sustenta que a diversificação das culturas jovens é, em si mesma, a reivindicação de uma diferença no interior da "cultura do consenso", de um espaço próprio que não seja subsumido à identidade nacional. Tais produções, para além dos estigmas que continuam pesando sobre elas, adentraram o espaço da principal emissora do país através de uma geração de artistas e intelectuais refratária ao uso autoritário do nacionalismo e já socializada, em grande medida, pela indústria cultural.

Dois processos ajudam a entender essa mudança. Em primeiro lugar, a emergência de uma nova estrutura de sentimentos em que pesa o anti-intelectualismo e o valor da "diversidade" em contraposição ao nacionalismo. Em segundo lugar, o fato de que esta estrutura de sentimentos demarca uma diferença em relação à geração anterior de artistas e intelectuais consagrados no campo cultural brasileiro. Como lembra Yúdice, 
Se os próprios funkeiros não politizaram suas danças e a sua musica, eles agora estão, após o arrastão, inevitavelmente envolvidos num conflito de validações que acontece nas esferas públicas. E sua contribuição para a política cultural carioca foi a de abrir o espaço do gosto, do estilo e do prazer, que não é permeado pela identidade nacional ou regional, mesmo que eles estejam usando o mesmo espaço físico do samba, do futebol ou do carnaval (Yúdice, 2004: I82).

Interessa, aqui, enfatizar a maneira como, a partir da experiência de afirmação do funk no cenário carioca, adensa-se uma tendência à visibilidade midiática positiva da periferia para o qual o Núcleo Guel Arraes foi decisivo. Como foi dito, este projeto de "visibilidade afirmativa" é assumido, particularmente pelo próprio Guel, por Regina Casé e pelo antropólogo Hermano Vianna, consultor e redator dos principais programas voltados a esta tendência. Para eles, a proposição de uma "estética da periferia" é estreitamente ligada com o que entendem como uma "atuação política" - ao menos, a possível - no interior da Rede Globo e da própria lógica da indústria cultural. Nas entrevistas dadas por ocasião do lançamento do Central da Periferia, Guel Arraes demonstrou ter plena consciência do modo como o posicionamento ideológico do grupo, que se insinuava já nas propostas do Programa Legal e do Brasil Legal, assim como dos vários quadros acolhidos pelo Fantástico, reaparecia, agora de modo mais assumido, nesse programa. A partir de um show ao ar livre, comandado por Regina Casé com a participação de artistas locais, o Central da Periferia apresentava os circuitos alternativos de produção cultural de bairros pobres do Rio de Janeiro, São Paulo, Recife, Salvador e Belém. A música era a principal atração, mas o programa, que era mensal, intercalava o registro dos shows com a apresentação de projetos sociais e peculiaridades regionais. "Agora não basta mostrar. É hora de politizar, de promover a reflexão", declarou Guel à revista Época, a respeito do programa (Chaves, 2007: 80-82). "O Central é o resultado tanto de uma postura mais ideológica quanto de um discurso sociológico mais assumidos. [...] Passamos a ter uma postura mais política, a tomar uma posição na direção de uma outra política. Há hoje um discurso mais amadurecido sobre a periferia, que não é partidário, mas que nos permite entrar na discussão em vários níveis, incluindo até o regional”, complementa o diretor. Para Regina Casé, a finalidade dos programas comprometidos com essa "visibilidade afirmativa" não é apenas o entretenimento: "o trabalho não é uma escolha, é quase uma atuação política. [...] O Central é uma questão de justiça televisiva; surgiu para mostrar um movimento de massa que era ignorado: eu achava uma loucura ir a um lugar ver milhares de pessoas cantando uma letra e dançando uma coreografia e, ao voltar para a Zona Sul, notar que ninguém conhecia aquilo", explica (Chaves, 2007: 63).

O Esquenta, programa dominicial sob o comando de Regina Casé, é o produto mais recente desta corrente. Ele estreou em 2oI I e, desde então, 
já na música de abertura, um samba anuncia o papel da anfitriã como mediadora entre a Globo, o público e a periferia:

\author{
Alô, Regina \\ É tão gente fina que sabe chegar \\ em qualquer esquina \\ Lá na cobertura, na laje ela está \\ É quem domina \\ Porque tem a sina de ser popular
}

O efeito de proximidade com a periferia é dado, antes de mais nada, pela própria composição do programa e pela disposição cênica dos convidados, muitos dos quais mais parecem estar em casa. Regina Casé está no centro de uma grande "roda de samba" musicalmente eclética, com Arlindo Cruz comandando a batucada sob os olhares atentos e animados de atores ligados às produções do NGA, como Douglas Silva, além de comediantes e da cantora Preta Gil. Um canto superior do cenário está reservado a garis que dançam e animam o auditório. Crianças também são presença constante no programa. Este grupo recorrente é nomeado de "família Esquenta" e recebe, a cada edição, convidados do mundo da música, da TV ou figuras destacadas para debater temas de interesse.

O caráter anti-intelectualista da estrutura de sentimentos desses artistas e intelectuais permite uma maior partilha de gostos entre eles e o mundo do funk, do axé, do tecnobrega, do rap, da música sertaneja, sem deixar para trás a reverência ao velho samba na figura de Arlindo Cruz, que é uma espécie de mestre de cerimônias do programa. Na verdade, se o samba pode ser visto como o núcleo duro da "cultura do consenso" de viés nacionalista, justamente aquela à qual se contrapõe o valor da diversidade expresso nas culturas juvenis como o funk, seu uso no programa sugere que ele continua indispensável para a construção de uma imagem positiva da periferia, especialmente a carioca. Mas esse uso implica uma marcação mais explícita do seu lugar social, em contraposição à sua diluição na identidade nacional, e o termo "periferia" vem trazer essa carga semântica. Os garis dançando, a predominância de negros e mestiços no cenário, a presença dos cantores Arlindo Cruz e Péricles, tudo leva a uma tentativa de extrair o samba do registro ideológico do nacional para reinseri-lo naquele da autoestima das classes populares. Lembramos que, no primeiro registro, o popular desliza quase inevitavelmente para o nacional, enquanto aqui, mesmo que isso possa acontecer, as diferenças entre os dois são mais marcadas. Além disso, apesar do destaque dado pelo programa ao samba, ele é uma espécie de anfitrião para ritmos e vertentes da produção cultural que dificilmente caberiam na rubrica do nacional, o que sinaliza a maneira complexa através da qual esta rubrica passa a se combinar com o valor da diversidade que marca o discurso e as iniciativas disseminados pela UNESCO, e que influencia as políticas culturais do governo federal desde a gestão Lula. 
O Esquenta vai ao ar nos meses de verão, mas tem uma edição especial de São João, que vamos analisar mais de perto em seguida. Em 20I I, esta edição foi dedicada ao São João do Nordeste, mas em 20I2, como disse a própria apresentadora, optou-se por um "outro caminho", e o programa "pegou uma pick-up lá pra dentro e resolveu fazer uma festa inspirada no interior de São Paulo, de Minas, do Mato Grosso, Mato Grosso do Sul, Paraná..., dos lugares onde a cultura caipira se enraizou" (todas as citações referentes ao programa foram extraídas da edição exibida em 24/o6/20I2). Por isso, os convidados da vez foram as duplas sertanejas Chitãozinho \& Xororó, João Bosco \& Vinicius, João Neto \& Frederico, diletos representantes do que João Marcos Alem chamou de "nova ruralidade brasileira" (I996). Ela foi configurada na segunda metade do século $\mathrm{XX}$ no contexto da industrialização de atividades agrícolas e da racionalização da produção rural, com a introdução de técnicas, insumos e profissionais que elevaram o patamar de produtividade daquelas atividades e diminuíram as diferenças entre as lógicas de produção, circulação e consumo entre os setores primário e secundário. Ao mesmo tempo, a consolidação de um mercado internacional de música, neste caso, colocou em diálogo a cultura caipira amadurecida nas primeiras décadas do século com matrizes culturais norte-americanas, notadamente o country, e, deste diálogo, nasceu a música sertaneja (Alem, I996). No primeiro quadro da edição de 24 de junho, a entrevista com Chitãozinho e Xororó tanto presta contas àquela matriz tradicional e propriamente caipira quanto assinala as influências americanas. A homenagem a Mazzaropi veio com a exibição de um trecho curto do filme Tristeza do Jeca, de ig6r. Regina Casé pede "muitas palmas mesmo para Mazzaropi, que este ano estaria fazendo, assim como Luiz Gonzaga, Ioo anos". A referência tanto a um quanto ao outro aproxima as duplas sertanejas convidadas do ideário nacionalista que lhes concede legitimidade enquanto representantes da cultura brasileira. Mas, a partir desta filiação, vem a afirmação da diferença em relação àquele ideário pela assunção das influências norte-americanas e pela recusa de um ideal de pureza em relação à identidade nacional no âmbito da cultura. Xitãozinho explicita: "a gente disse, peraí, a música caipira não pode ficar só na viola, tem que acompanhar a evolução". E, perguntado sobre as influências musicais e estéticas sofridas, eles apontam os Beatles e o cabelo de Rod Stewart.

A recusa da tradição vem também por sua identificação semântica a um estado de miséria que acometia boa parte da população brasileira e pela celebração das "novidades" quanto à situação dos pobres. Recordando o velho hábito de pintar os dentes de preto para representar o caipira nas festas de São João, Regina Casé explica que isso significava a falta de acesso ao dentista e aos cuidados com os dentes, o que levava à perda da dentição na idade adulta. E celebra o fato de que esta "tradição" está em franco declínio: "atualmente, no Brasil, metade das crianças até I2 anos nunca tiveram cárie e, de 2003 pra cá, I7 milhões de brasileiros passaram a ir ao dentista". 
Em vários momentos do programa, as mudanças do mundo caipira são enfatizadas e são utilizadas como sintoma de uma mudança mais geral da sociedade brasileira, de uma maior visibilidade do que não está no centro, seja ele entendido como o interior em relação ao litoral ou como a periferia em relação à "Zona Sul". Atestados deste novo estado de coisas, são chamados ao palco "Os mutilados", um grupo de rap com sotaque caipira de Piracicaba; ou, ainda, o especialista em novas tecnologias Ronaldo Lemos, que é apresentado como "um dos primeiros caras no Brasil que sacou que isso tudo tava acontecendo com a chegada das novas tecnologias...".

O discurso da transformação social do Brasil a partir da visibilidade das margens reencontra a temática classista e ganha força com a participação das atrizes Leandra Leal, Taís Araujo e Izabela Drummond, que interpretam três empregadas domésticas vítimas de patrões injustos na novela Cheias de Charme. O mais importante é que elas fazem a clássica trajetória das mocinhas no melodrama e, a partir desta situação decaída, dão a volta por cima ao formarem um grupo musical de sucesso, as Empreguetes. A novela é um marco no uso das novas tecnologias para fidelização e conquista da audiência, mas o interesse aqui é destacar o quanto ela está sendo promovida como uma mudança na tomada de posição da Globo em relação ao conflito de classes, no caso, retratando patroas malvadas perseguindo empregadas nas relações de trabalho, que são, assim, denunciadas como injustas. Leandra Leal reforça: "além da gente tá dançando, cantando, fazendo um grupo musical que é muito divertido, eu me sinto muito feliz de estar fazendo uma novela em que três empregadas domésticas são protagonistas. Isso tudo que você tá falando aqui e que o Esquenta representa e essa mudança que a gente tá tendo, a utilização da internet, eu me sinto assim, cara, eu tô fazendo um negócio que eu acredito muito, muito mesmo". A filiação entre a visibilidade dos pobres na novela e aquele projeto estético-político mencionado por Guel Arraes é assinalada por Taís Araújo: “é uma transformação, a gente tá fazendo parte, assim, igual a você. Eu acho que o Esquenta existir é uma conquista, você batalhou desde... Não tenho dúvida de que a sua batalha, todos os programas que você fez, incluindo essa conquista do Esquenta, abriu portas para existir uma novela como essa nossa". Casé reconhece, mas sugere que a penetração desta concepção no produto mais nobre da televisão assinala uma outra fase: "a gente fala isso há anos... esse pessoal que não aparece na televisão... agora a gente não pode mais falar nada disso. Tudo isso caducou e dá a maior felicidade".

Mas um outro quadro do programa mostra o quanto é difícil escapar de uma perspectiva moralista própria do melodrama no tratamento das relações de trabalho, mesmo quando se trata daquela relação em que o(a) trabalhador(a) está na situação mais frágil, sem sequer a limitação legal da jornada. O Esquenta promoveu um concurso de três duplas formadas por pa- 
troas e empregadas que dançavam e cantavam sucessos no palco. Em todos os relatos transparecia a amizade e o afeto que ligava cada dupla, mas um em especial apelou para a oposição entre "patroa boa" e "patroa má". Foi o caso de uma empregada que teve seus documentos e o endereço da família destruídos por uma patroa como vingança por um suposto roubo e que foi ajudada pela nova patroa a localizar seus parentes no interior da Bahia. A reconciliação no palco reproduz o andamento da própria trama da novela, em que cada vez mais a polarização entre as "boas" e as "más" patroas toma o lugar da denúncia das injustiças do trabalho doméstico, inclusive porque, agora pelo menos uma das "empreguetes" se tornou patroa, no caso, uma patroa bondosa e muito compreensiva com uma empregada que trama contra ela.

$\mathrm{Na}$ verdade, mais do que uma tensão entre um tratamento político ou moralista do tema, temos aqui o velho hábito próprio à cultura brasileira funcionando no sentido de deslocar o conflito do centro da cena, para fazer crível a promessa de que, nesta sociedade, há lugar para todos. Mesmo que boa parte da trajetória do NGA tenha sido dedicada a alargar os limites da representação para incluir grupos e culturas com pouca visibilidade, o que significa admitir uma assimetria de poder, convém não subestimar o poder de atração do mito da "pátria mãe gentil" a que a Globo adere sem muitas reservas. Neste sentido, o nacional-popular que marcou os usos políticos das obras de Gonzagão e Mazzaropi não está totalmente em desuso, uma vez que a crença na resolução simbólica dos conflitos de classe parece persistir, reatualizando aquela "cultura do consenso" a que se referia Yúdice. Mas, como o valor da diversidade também caracteriza a estrutura de sentimentos desta geração de artistas e intelectuais, tal integração não pode mais ser pensada exclusivamente através da diluição dos conflitos de classe na rubrica do nacional. A visibilidade é dos pobres, mas é também dos portadores de deficiência, dos gays e lésbicas, dos obesos e da dimensão da raça que não pode ser subsumida à classe social, tudo metaforizado como "periferia". ${ }^{\mathrm{I}}$ De certo modo, é como se a concepção de "democracia racial" (Freyre, I963) fosse dilatada para englobar uma "democracia" que envolve também as relações de classe, de gênero etc.

Na edição do Esquenta, mais uma vez vemos Natália funcionando como o exemplo de uma deficiente visual integrada à vida social, que "larga a bengala pra dançar" no palco. Ou ainda, no quadro "correio elegante", em que apaixonados mandavam recados para seus parceiros, assistimos a Gilmara fazer uma declaração de amor para Preta Gil, que interpreta a sua namorada Julie. Regina Casé assinala a relação entre as diversas facetas da política de visibilidade que orienta o programa: "antigamente, quando a gente não podia fazer uma declaração de amor para uma pessoa do mesmo sexo na televisão, naquele tempo do Jeca Tatu e dos dentes pretos... agora a gente pode falar que a Gilmara ama a Julie". 
O valor da diversidade talvez seja o elemento mais pervasivo desta estrutura de sentimentos e a sua diferença mais marcada em relação àquela da brasilidade revolucionária que caracterizou uma geração anterior de artistas e intelectuais. Ele esteve muito presente nas políticas culturais do governo Lula e assumiu a forma de um conceito antropológico de cultura que amplia o rol de manifestações vistas como merecedoras dos incentivos fiscais. Tal noção mais antropológica e menos erudita de cultura reforça as posições dos produtores e consumidores mais distantes do cânone modernista ao problematizar a diferença entre a "alta" e a "baixa" culturas. Indicativo deste fato é a concessão do prêmio da Ordem do Mérito Cultural a membros do Casseta \& Planeta pelo presidente Lula e pelo ministro da Cultura, Gilberto Gil, em 2003. Chama a atenção a heterogeneidade dos premiados, desde Cândido Portinari (pintor modernista) a Pixinguinha (sambista tradicional). ${ }^{2}$

Muitos são os impasses gerados pelo alargamento da concepção de cultura no âmbito das políticas públicas (Botelho, 2007), mas o interesse, aqui, é simplesmente destacar uma possível relação entre a estrutura de sentimentos dos membros do NGA e a experiência social que suas produções simbolizam a partir de valores específicos. Neste sentido, a ligação fundamental entre estas produções e a sociedade abrangente é, sobretudo, a maior visibilidade dos pobres na cena política, econômica e cultural desde a redemocratização. Com a crise econômica, a abertura política e a crescente mobilização vividas naquele período, a construção da hegemonia passava cada vez mais pela conquista desta parcela da sociedade que, durante a Ditadura Militar, havia sido aplacada com a estratégia do pão e circo, sustentada pelo incremento do consumo e pela propaganda (Rocha, 20Io, cap. I). Do ponto de vista econômico, desde o Plano Real, os segmentos do mercado situados mais abaixo na pirâmide passaram a contar decisivamente para as empresas, provocando uma corrida por este tipo de audiência na TV e no setor publicitário, processo intensificado no começo do século XXI pelo aumento dos níveis de emprego, do valor do salário mínimo e pelas políticas sociais. Finalmente, no âmbito da cultura, a visibilidade dos pobres se fez notar com muita força no cinema, na TV e na música, tanto na produção sustentada pelo mercado quanto nas políticas culturais do governo federal.

Se, desde o seu surgimento, a cultura de massas foi o espaço de borramento das fronteiras entre o erudito e o popular (Martín Barbero, 1987; Cohn, I973) a atuação do NGA supõe um outro borramento, desta vez, entre a própria cultura de massas e a produção legitimada como inovadora do ponto de vista estético e político. Um ponto alto desta tendência foi a exposição "estética da periferia", realizada no Rio de Janeiro em 2005, e, depois, em outras capitais. Uma de suas idealizadoras, a pesquisadora Heloísa Buarque de Holanda, a definiu como "uma exposição sobre a visualidade e a linguagem cultural da periferia do Rio de Janeiro, retratando sua maneira de captar o mundo da mídia 
e da moda de forma antropofágica, transformadora e criativa, dentro de sua realidade econômica" (entrevista disponível em <www.heloisabuarque dehollanda.com.br>). Indo além, ela afirma: "é inquestionável a importância dessas expressões culturais no conjunto da diversidade que nos caracteriza. Não podemos definir identidade cultural nacional, simplesmente porque ela não existe no singular. Nossa cultura é plural e as estéticas centrais e periféricas, como o tecnobrega de Belém, o funk carioca ou o hip hop paulistano, compõem essa multiplicidade, sendo cada vez mais reconhecidas, também por isso" (ver entrevista). A referência à antropofagia e à identidade nacional, agora, no plural, indica que, mais do que a renúncia à antiga forma de consagração, temos aqui o aumento da disputa em torno do poder de definir os critérios de legitimidade cultural, e o fato de que a visibilidade midiática passa a contar como um recurso importante nessa disputa - como, de resto, tem contado nos campos político, religioso etc. De todo modo, parece haver uma disputa mais franca entre atores situados nos diferentes ramos da produção erudita, nas vertentes mais tradicionalistas ou contemporâneas de cultura popular, nos filões mais afluentes ou limitados do mercado.

Convém, então, lembrar o lugar de fala deste projeto de visibilidade afirmativa da periferia, que faz parte de uma tentativa de reconstrução da imagem da Rede Globo em compasso com mudanças do espaço público brasileiro desde a redemocratização. A reformulação dos jornais locais de modo a abrir mais espaço para o "jornalismo comunitário"; a inserção em telenovelas de temas caros a movimentos sociais, como o racismo e o homoerotismo; as propostas de "responsabilidade social", como o Criança Esperança e o Ação Global explicam-se pelas mesmas razões. A contradição está em que as iniciativas da Globo sensíveis aos penalizados pela distribuição de poder e riqueza servem para justificar sua atuação como uma força que ajuda a produzir aquela assimetria, na medida em que concentra enorme poder e riqueza e ainda legitima interesses de outros que fazem o mesmo, no mercado e na política. A superação deste estado de coisas exigiria a democratização da mídia no Brasil, no sentido de ampliação das possibilidades de fala de outros atores além dos grandes veículos de comunicação. Neste sentido, se contribuiu fortemente para a consagração cultural da periferia, ao falar em seu nome, a Globo não deixa de ajudar a produzir o seu silenciamento. 


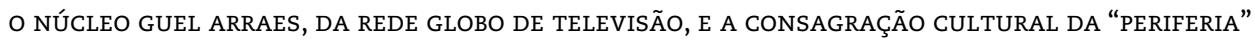

574

Maria Eduarda da Mota Rocha é professora do Departamento e do Programa de Pós-Graduação em Sociologia da Universidade Federal de Pernambuco (UFPE), mestre e doutora em Sociologia da Cultura pela Universidade de São Paulo (USP), e egressa do Programa de Formação de Quadros do CEBRAP. É autora dos livros A nova retórica do capital - A publicidade brasileira em tempos neoliberais (2010) e Pobreza e cultura de consumo em São Miguel dos Milagres (2002). 


\section{NOTAS}

I Na verdade, a força discursiva da "diversidade" transcende as produções do NGA e encontra muito eco nas produções audiovisuais da própria "periferia", como aquelas agrupadas no Festival Audiovisual Visões Periféricas e no Fórum das Experiências Populares em Audiovisual. Também neste âmbito, o conceito de "periferia" foi expandido para além de sua dimensão geográfica, em direção semelhante à que vemos no Esquenta. Sobre as produções audiovisuais da "periferia", ver Andrade (2013).

2 Matéria de 19 de dezembro de 2003, disponível no site do Ministério da Cultura. Acesso em 2 de jun. 20 I I.

\section{REFERÊNCIAS BIBLIOGRÁFICAS}

Alem, João Marcos. (I996). Capira e country: A nova ruralidade brasileira. Tese de Doutorado. FFLCH/Universidade de São Paulo.

A história completa do Casseta \& Planeta, vol. 2. (2005). São Paulo: Abril.

Andrade, Michely. (2013). As experiências populares em audiovisual. Tese de Doutorado. PPGS/Universidade Federal de Pernambuco.

Arruda, Maria Arminda do Nascimento. (200I). Metrópole e cultura. São Paulo no meio século XX. São Paulo: Edusc.

Arruda, Maria Arminda do Nascimento. (2010). Sociologia da cultura e sociologia da comunicação de massa: esboço de uma problemática. In: Martins, Carlos Benedito \& Martins, Heloisa H. T. de Souza (orgs.). Horizontes das ciências sociais no Brasil: sociologia. São Paulo: Barcarolla, p. 253-277. Bakhtin, Mikhail. (2008). A cultura popular na Idade Média e no Renascimento: o contexto de François Rabelais. São Paulo/ Brasília: Hucitec/Ed. UnB.

Martín Barbero, Jesús. (1987). De los medios a las mediaciones. Comunicación, cultura y hegemonía. Barcelona: Editorial Gustavo Gili.

Botelho, Isaura. (2007). Dimensões da cultura e políticas públicas. São Paulo em Perspectiva, I5/2, p. 73-83.

Bourdieu, Pierre. (2007). O mercado dos bens simbólicos. In: Miceli, Sergio (org.). A economia das trocas simbólicas. São Paulo: Perspectiva, p. 99-I8I. 
Bourdieu, Pierre (2007). A distinção: crítica social do julgamento. São Paulo/Porto Alegre: Edusp/Zouk.

Candido, Antonio. (1965). Literatura e sociedade: estudos de teoria e história literária. São Paulo: Cia. Editora Nacional.

Chaves, Sarah Nery Siqueira. (2007). "Tenho cara de pobre”: Regina Casé e a periferia na TV. Dissertação de Mestrado. ECO/Universidade Federal do Rio de Janeiro.

Cohn, Gabriel. (1973). Sociologia da comunicação: teoria e ideologia. São Paulo: Pioneira.

Fechine, Yvana. (2008). Núcleo Guel Arraes: formação, influências e contribuições para uma TV de qualidade no Brasil. In: Fechine, Yvana \& Figueroa, Alexandre (orgs.). Guel Arraes - um inventor no audiovisual brasileiro. Recife: CEPE, p. I7-88.

Freyre, Gilberto. (1963). Casa-grande \& senzala. Brasília: Ed. UNB. Ginzburg, Carlo. (1987). O Queijo e os vermes: o cotidiano e as ideias de um moleiro perseguido pela inquisição. São Paulo: Companhia das Letras.

Hollanda, Heloisa Buarque de. (2004). Asdrúbal trouxe o trombone. Rio de Janeiro: Aeroplano.

Holanda, Heloísa Buarque de. Entrevista. Disponível em $<$ www.heloisabuarquedehollanda.com.br $>$. Acesso em 2 de jun. 20II.

Huyssen, Andreas. (2010). Modernismo después de la posmodernidad. Barcelona: Gedisa.

Huyssen, Andreas. (2002). Después de la gran división. Buenos Aires: Ed. Adriana Hidalgo.

Jameson, Fredric. (1996). Pós-modernismo: a lógica cultural do capitalismo tardio. São Paulo: Ática.

Lafetá, João Luis \& Cândido, Antonio. (2000). I930: A crítica e o modernismo. São Paulo: Ed. 34.

Leão, Ana Carolina Carneiro. (2008). A nova velha cena: a ascensão do Mangue Beat no campo cultural pernambucano. Tese de Doutorado. PPGS/Universidade Federal de Pernambuco. Lima, Luiz Costa. (I978). Teoria da cultura de massa. 2. ed. São Paulo: Paz e Terra.

Machado, Arlindo. (2000). A televisão levada a sério. São Paulo: Senac. 
Miceli, Sergio. (1984). Entre no ar em Belíndia. A indústria cultural hoje. Cadernos IFCH, I5, p. I-47.

Miceli, Sergio. (I982). A noite da madrinha. São Paulo: Perspectiva.

Ministério da Cultura. (2009). Plano Nacional de Cultura Anexo ao Projeto de Lei $n^{\circ} 6.835$, Brasília.

Miranda, Orlando Pinto. (I975). Tio Patinhas e os mitos da comunicação. Dissertação de Mestrado. FFLCH/Universidade de São Paulo.

Ortiz, Renato. (I988). A moderna tradição brasileira. São Paulo: Brasiliense.

Ortiz, Renato. (2006). Cultura brasileira e identidade nacional. São Paulo: Brasiliense.

Ridenti, Marcelo. (2005). Artistas e intelectuais no Brasil pós-I960. Tempo Social, I7/I, p. 8I-Iıo.

Ridenti, Marcelo. (2000). Em busca do povo brasileiro: artis tas da revolução, do CPC à era da TV. Rio de Janeiro: Record. Rocha, Maria Eduarda da Mota. (2008a). O Núcleo Guel Arraes e a reconstrução da imagem da Globo. In: Fechine, Yvana \& Figueroa, Alexandre (orgs.). Guel Arraes: um inventor no audiovisual brasileiro. Recife: CEPE, p. 93-I IO.

Rocha, Maria Eduarda da Mota. (2008b). Guel Arraes: Leitura social de uma biografia". In: Fechine, Yvana \& Figueroa, Alexandre (orgs.). Guel Arraes: um inventor no audiovisual brasileiro. Recife: CEPE, p. III-I26.

Rocha, Maria Eduarda da Mota. (2002). O consumo precário: pobreza e cultura de consumo em São Miguel dos Milagres. Maceió: Edufal. (Coleção Estudos sobre Alagoas, I).

Taschner, Gisela. (1978). Do jornalismo político à indústria cultural. Tese de Mestrado. FFLCH/Universidade de São Paulo. Vianna, Hermano. (1987). O baile funk carioca. Dissertação de Mestrado. PPGAS/Universidade Federal do Rio de Janeiro.

Williams, Raymond. (2000). Marxismo e literatura. Barcelona: Peninsula.

Wisnik, José Miguel. (I982). O nacional e o popular na cultura brasileira - música. São Paulo: Brasiliense.

Yúdice, George. (2004). A conveniência da cultura: usos da cultura na era global. Belo Horizonte: Ed. UFMG. 


\section{O NÚCLEO GUEL ARRAES, DA REDE GLOBO DE TELEVISÃo, E A CONSAGRAÇÃo CULTURAL DA “PERIFERIA" \\ Resumo}

Desde a década de I980, uma geração de artistas e intelectuais tem contestado a oposição entre "alta" e "baixa" culturas e se valido de seu capital midiático para produzir programas de TV em que desponta uma nova estrutura de sentimentos anti-intelectualista, apegada ao valor da "diversidade", refratária ao nacionalismo, ao partidarismo e a uma visão tradicionalista de "povo". Esta geração tem no Núcleo Guel Arraes (NGA), da Rede Globo, um espaço institucional e simbólico muito importante. Para entender esta estrutura de sentimentos e apontar de que maneira ela ecoa e intensifica uma mudança no campo cultural brasileiro, este artigo está dividido em dois itens que tratam, respectivamente da estrutura de sentimentos dos artistas e intelectuais abrigados no NGA e da conversão desta estrutura de sentimentos em um projeto estético-político de visibilidade midiática da periferia, sobretudo a partir do programa dominical Esquenta, da Rede Globo.

\section{THE NÚCLEO GUEL ARRAES OF GLOBO TELEVISION NETWORK AND THE CULTURAL CONSECRATION OF "PERIPHERY"}

\begin{abstract}
Since the I980s, a generation of artists and intellectuals has contested the opposition between "high" and "low" culture and has used its media capital to produce TV programs that expresses its new structure of feelings, more attached to the value of cultural diversity, against nationalism and a traditional vision of "people". This generation has found an important institutional and symbolic place in the Núcleo Guel Arraes (NGA), of Globo $\mathrm{TV}$. In order to understand this structure of feelings and to point how it echoes and intensifies a cultural change in the Brazilian cultural field, this article is divided in two items that present the structure of feelings embraced by artists and intellectuals sheltered in the NGA and the affirmative visibility of the "periphery", especially in the Globo's television program named Esquenta.
\end{abstract}

\section{Palavras-chave}

Núcleo Guel Arraes;

Periferia; Campo cultural;

Estrutura de sentimentos;

Rede Globo.

\section{Keywords}

Núcleo Guel Arraes;

"Periphery"; Cultural field;

Structure of feelings;

Globo TV. 